\title{
Formas de disjunção no haiku: algumas características do haiku em búlgaro e em português
}

\section{Resumo:}

O haiku, a forma poética mais breve, com origem na cultura japonesa, está a conquistar o mundo ocidental e a desafiar a crítica literária. O objetivo da nossa comunicação é analisar e comparar haiku de poetas búlgaros (M. Liubenova, P. Chuhov, M. Ribarova, etc) e de poetas portugueses (Luisa Freire, José T. Mendonça, Casimiro de Brito), com base no processo de disjunção de imagens que opera nas duas línguas. Assim, esperamos perceber como os poetas búlgaros e portugueses contribuem para a riqueza do haiku ocidental.

Palavras-chave: cultura japonesa, poesia, haiku, disjunção, poetas

\begin{abstract}
:
Forms of Disjunction in the Haiku: Some Characteristics of Haiku in Bulgarian and in Portuguese

The haiku, the briefest poem, originated in the Japanese culture, is conquering the Western World, challenging the literary critics. The objective of the present communication is to analyze and compare haiku poems of Bulgarian poets (M. Liubenova, P. Chuhov, M. Ribarova) to haiku poems of Portuguese poets (Luisa Freire, José T. Mendonça, Casimiro de Brito), on the basis of the disjunction process, operating in both languages. Thereby, we hope to show the contribution of the Portuguese and Bulgarian poets to the originality of the occidental haiku.
\end{abstract} Keywords: Japanese culture, poetry, haiku, disjunction, poets 


\section{Introdução}

A presença indiscutível do haiku no horizonte literário da Bulgária e de Portugal torna cada vez mais relevante uma reflexão sobre as suas características e manifestações nestes dois países. De facto, nas últimas décadas estamos a assistir à emergência de uma forma ocidental de haiku que evidencia o desenvolvimento e a modernização do padrão oriental. Segundo Ban'ya Natsuishi, "a modernização do haiku japonês caracteriza-se pela predominância de um imaginário psicológico e mental" (2018: 78). Assim, o poema mais breve já merece a atenção da crítica literária como qualquer outro modelo poético, evoluindo no espaço literário.

Observando os dois exemplos seguintes, podemos destacar algumas características gerais do haiku que captam logo a atenção:

tarde de inverno:/ainda voam as gaivotas/e os guarda-chuvas (Domingos, 2010: 126)

música silenciosa/o caracol quando sobe/na parede branca (de Brito, 2018: 82)

- a brevidade do poema: dizer pouco significar muito; significar sem dizer;

- a simplicidade do vocabulário quotidiano: palavras concretas, banais;

A simplicidade, a pobreza e a imperfeição, princípios estéticos e éticos, têm as suas raízes na história do Japão, especialmente, no período Sengoku, 1466-1598, caracterizado por guerras intermináveis e destruições. A partir dessa época, a pobreza e a simplicidade dos objetos, do vestuário e da habitação, ganharam um valor estético (Koren, 2015).

- o valor sugestivo da expressão caracteriza toda a estética japonesa; não há mimésis, nem realismo;

- a estrutura formal de três linhas de 5/7/5 sílabas respetivamente; o haiku moderno foge a esta regra. Qual a origem desta estrutura?

O texto introdutório de Makoto Kemmoku e Dominique Chipot, acompanhando L'intégrale des haikus de Basho (2012: 9-15), oferece 
uma aproximação histórica da origem do haiku. O renga, poema ligado, criado por um grupo de 8 poetas, representa uma alternância de estrofes longas e estrofes curtas. Desenvolveu-se entre o século XII e XVI. Pode-se distinguir o renga clássico, praticado pela aristocracia e o renga ligeiro, reservado aos poetas da pequena nobreza, aos monges budistas e aos sábios. Progressivamente este último tipo de renga passou a ser designado por haikai. A primeira estrofe, designada por hokku, tinha a estrutura de 5/7/5 sílabas, sabendo-se que a sílaba nas línguas ocidentais nem sempre corresponde à mora em japonês, marcada pela duração: longa ou curta. No início do século XX, o renga já não existia, mas os poetas continuavam a escrever hokku, a primeira estrofe do haikai. Foi o grande poeta Shiki que criou o neologismo haiku para designar esta estrofe independente que passou a ter vida própria;

- a palavra sazonal, kigo; as estações são diretamente designadas, ou por metonímia. Por exemplo, a neve indica o inverno, as folhas amarelas - o outono;

- rutura, interrupção, vazio, silêncio, kireji; a rutura na estrutura do haiku tem a função de abrir um espaço entre as palavras ou depois das palavras, onde o sentido fica livre de uma forma verbal explícita (e explicativa) e, desta maneira, ganha o poder do sentido implícito, plural, indeterminado, até silenciado;

- wabi-sabi; as duas palavras encontram-se pela primeira vez no século VIII, na mais antiga antologia da poesia japonesa. Quase sinónimas, as ideias que elas veiculam são: simplicidade, impermanência das coisas e dos seres, a beleza do imperfeito, o valor estético da pobreza, o prazer na solidão. Wabi determina a tonalidade do haiku.

\section{Vista panorâmica sociocultural da poesia haiku na Bulgária e em Portugal}

$\mathrm{Na}$ literatura búlgara a forma poética do haiku aparece em finais dos anos 80 . Desde essa época, o poema breve continua a conquistar cada vez mais espaço na literatura. 
A primeira coletânea de haiku foi publicada em 1988, Gorata na gluharcheto (A floresta do dente-de leão) pelo poeta e tradutor Dimitar Stefanov. No ano 2000 foi criado o Haiku Clube Búlgaro. Em 2003 nasceu o Haiku Clube Plovdiv e em 2008 - União Búlgara de Haiku. Em 2013 aparece a revista Haiku mundo (Haiku sviat), que tem uma função informativa, educativa e científica. Destacam-se publicações de livros e antologias de haiku em búlgaro com tradução em francês e/ou em inglês. Algumas antologias importantes: Ombres et lumières (anthologie de haiku francofone, 2003), O canto da Água, haiku escrito por crianças (2004), Espelhos (2005); A cidade (2012), Beyond words (2018). Organizam-se recitais e espetáculos de teatro, baseados em haiku como, por exemplo, o recital de haiku de Pedro Tamen e Guinka Biliarska. Aparecem teses de doutoramento (L. Balabanova, A força do não-dito), ensaios sobre o budismo, o xintoísmo, as formas do teatro japonês; multiplicam-se seminários, conferências, encontros. Traduzem-se ensaios de Jane Reichhold sobre as regras do haiku. Publicam-se traduções de haiku de poetas portugueses: Casimiro de Brito, Pedro Tamen, Ana Hatherly. Organizam-se concursos e festivais (Ohanami - Contemplação das cerejeiras em flores), festas da arte do papel. Os poetas de haiku ganham prémios em concursos internacionais e nacionais, publicam em revistas internacionais: Petar Chuhov, Liudmila Blabanova, Lidia Lecheva, Maya Kisiova, Maya Liubenova, Iliana Ilieva, Iliana Stoyanova, Alexandra Ivoylova, etc. Muitos poetas experimentam outras formas de poesia japonesa: tanka, haiga (imagem + haiku), haibun (narrativa breve + haiku).

Para terminar este breve panorama da evolução do haiku na Bulgária, seria interessante mencionar uma forma minimalista, chamada nava que aparece na poesia búlgara nos anos 80 . Segundo Ivan Metodiev (1990: $\left.\mathrm{n}^{\circ} 14\right)$, Nava, palavra com origem na mitologia eslava, é a designação de várias formas breves, incluindo o haiku. $\mathrm{O}$ estilo nava representa uma tentativa de criação de uma poesia breve original que combina modelos orientais e modelos ocidentais, mas que corresponde sobretudo à sensibilidade, ao pensamento e ao misticismo dos búlgaros. A forma nava tenta transmitir as sensações mais profundas em palavras simples, sem tenções poéticas. Neste sentido 
existe uma semelhança com o haiku, mas o estilo nava inclui também outras formas breves como o aforismo filosófico, a metáfora global, o fragmento. Poetas que experimentaram este estilo: Blaga Dimitrova, Alexander Guerov, Ekaterina Yossifova.

Vejamos o seguinte poema de Antoaneta Nikolova, citado no artigo acima referido:

През огледалото / минава сянка. / Във стаята не се променя нищо.

Uma sombra / Atravessa o espelho. / Nada muda no quarto ${ }^{1}$.

Em Portugal a situação parece diferente. Não há associação, nem revista, nem concursos nacionais. Antes do aparecimento da poesia haiku propriamente dita, podemos destacar algumas características da estética e do pensamento do Extremo Oriente que marcaram a sensibilidade poética de certos poetas portugueses. A obra de Catarina Nunes de Almeida sobre as marcas do pensamento estético do Extremo Oriente na poesia portuguesa contemporânea (Nunes de Almeida, 2015), apresenta o percurso original de alguns poetas portugueses que escrevem haiku. Modelos estéticos, éticos e espirituais aparecem na poesia de Ana Hatherly, Casimiro de Brito e Rosa Alice Branco.

Em Ana Hatherly, na obra Tisanas, 1969 (traduzida para o búlgaro), observamos uma certa reinvenção do koan budista (sentenças, aforismos, questões a base de paradoxos), e Na Via do Mestre de Casimiro de Brito é um diálogo in absência com Lao-zê.

Não entendo as trevas nem a transparência/ Entendo: Ouço em cada fragmento/o coração da Coisa; a constelação; o enigma (de Brito, 2000: 70)

Em princípio, os haiku de Casimiro de Brito, assim como a sua atitude perante a vida material, são marcados pelo pensamento taoista e budista, assimilado e transformado em estilo poético e maneira de viver.

Eis outros elementos formais que marcam a aproximação à poesia do Extremo Oriente: o indizível; o abandono do materialismo, das

\footnotetext{
${ }^{1}$ A tradução para português de todos os poemas é minha.
} 
metas para alcançar a sabedoria e a felicidade; a comunicação espontânea das emoções; o caráter fragmentário e aberto da obra; as referências à estética do Zen como a negação da perfeição absoluta, do caráter definitivo da obra; a importância da união com a natureza.

Neste contexto "pré-haiku" aparece em 1962 a primeira tradução de haiku japoneses, elaborada por Casimiro de Brito, Poemas orientais, coleção A palavra, $n^{\circ} 5$.

Segundo Catarina Nunes, "o fascínio" pela poética do Extremo Oriente em certos poetas portugueses, antes do aparecimento do haiku propriamente dito, relaciona-se com a estética imagista "que segue a linha de Ezra Pound no que respeita à justaposição das imagens e à aproximação entre a linguagem poética e a expressão pictórica" (2015: 116).

O modelo poético do haiku foi divulgado por Wenceslau de Moraes.

Depois da década de 80 , surge um número ainda bastante reduzido de poetas que escrevem obras próximas do cânone do haiku japonês. Podemos observar a presença de palavras sazonais na obra de Albano Martins, Com as flores do Salgueiro (1995), e na de Yvette Centeno, A Oriente (1998).

Mais tarde, o haiku português representa uma parte da obra poética de vários poetas como: Casimiro de Brito, Ramos Rosa, Herberto Helder, José Manuel de Vasconcelos, David Rodrigues, Luísa Freire, Leonilda Alfarrobinha, Albano Martins, José Tolentino Mendonça.

Para resumir este primeiro paralelo entre a vida do haiku na Bulgária e em Portugal, podemos dizer que, a partir de uma visão sociocultural, a diferença passa.

- pelas manifestações sociais, relacionadas ao haiku;

$\mathrm{Na}$ Bulgária, o haiku tem uma presença marcada na vida literária. Pretende-se criar uma escola búlgara de haiku.

Em Portugal, quase não se destacam manifestações à volta do haiku. O blog de David Rodrigues (haikuportugal.blogspot.com) dá uma certa possibilidade aos poetas de divulgar os seus haiku e torna visível também algumas poucas atividades, ligadas ao poema, tais como 
ateliês na escola. Nas palavras de David Rodrigues, o haiku será uma escola.

- pela presença da cultura do Extremo Oriente na cultura nacional.

$\mathrm{Na}$ Bulgária esta presença é, por assim dizer, intelectual: licenciatura de Estudos Orientais, obras teóricas sobre a filosofia e a cultura do Oriente, traduções a partir do original da obra de Kung-ze, artigos, teses de doutoramento, obras sobre a história e a cultura do Japão, (Gabrovska, 2008); sobre o haiku e o Zen, (Ivanov, 2010); sobre a narrativa lírica japonesa (Krysteva, 1994), etc. Em princípio, estes académicos não são poetas, não escrevem haiku.

Em Portugal, o contato com as culturas orientais japonesa e chinesa, é mais emotivo e pessoal. Vejamos as obras de Ana Hatherly, Casimiro de Brito, José Manuel de Vasconcelos, sem esquecer a de António Graça de Abreu. Podemos ouvir o eco da estética oriental na obra poética de todos estes poetas. Muitas vezes a aproximação à cultura do Extremo Oriente é uma experiência vivida, uma sabedoria que marca profundamente a obra e a mentalidade do poeta. Porém, não faltam alguns estudos académicos, por exemplo: sobre Ana Hatherly: Os campos abertos do (in)dizivel de Raquel Henriques da Silva (Quimera Editores, 2003); sobre O ocidente e a poética esquiva do haiku de Manuel-Lourenço Forte e Manuel Pinto Ribeiro (Ed. Vega, 1995).

\section{Comparação de algumas características estruturais e temáticas do haiku búlgaro e do haiku português}

Será interessante ver como a diferença ao nível cultural entre a evolução do haiku búlgaro e a do haiku português se pode manifestar ao nível do modelo estrutural e dos temas, sem esquecer que os poetas dos dois países se tentam manter fiéis ao cânone original e, ao mesmo tempo, procuram enriquecer o haiku com aspetos inovadores, baseados na especificidade das respetivas culturas e línguas nacionais.

Tendo em vista as diferenças essenciais entre as línguas ocidentais e a língua japonesa, o haiku escrito numa língua ocidental parece impossível. O Japonês é uma língua aglutinante, cada caráter é uma sílaba, mora, longa ou curta. $\mathrm{O}$ caráter tem também um valor visual. 
A própria língua permite o minimalismo da expressão. A não linearidade da escrita possibilita a síntese, a brevidade, a combinação improvável de imagens e sentidos que dão origem à sugestão e facilitam a liberdade da leitura.

Por conseguinte, o haiku ocidental não possui muitas das características estruturais do haiku original, devido à diferença entre os dois sistemas verbais.

Em relação ao espírito do haiku, também não temos grandes hipóteses de descobrir o mistério do poema japonês, que é o resultado de uma visão holística do mundo, de uma estética da simplicidade e de um pensamento budista. Por outro lado, o haiku começa a ganhar vida num período histórico catastrófico, chamado Sengoku (1466-1598), que já referimos, e corresponde a um estilo de vida que transforma a pobreza em valor moral consciente. A simplicidade, o imperfeito, a banalidade recebem um valor estético. Isto é o estilo wabi que foi cultivado primeiro nas cerimónias de chá, das quais faziam parte a criação e a recitação de versos.

Quais são, então, os pontos de contacto entre as duas culturas poéticas que permitem aos poetas ocidentais escrever haiku? Os mais importantes serão: a sugestão imagética, a ambiguidade, a brevidade. A um outro nível, acrescentamos a sinceridade da emoção que abre a escrita.

Vejamos os haiku seguintes, escritos por poetas búlgaros e portugueses:

pequeno aquário / um peixe / atravessa o vidro

(Dinis Lapa, 2010: 62)

жажда / вкус на диня / по устните ти (Vessislava Savova, 2014: 131) sede / sabor de melancia / nos teus lábios

Os haiku citados evidenciam as características mencionadas: brevidade, imagens bem sugestivas de várias situações vividas, uma certa ambiguidade no haiku de Vessislava Savova, uma surpresa no haiku de Dinis Lapa. Resumindo: em todos estes exemplos podemos detetar 
o momento haiku: uma imagem concreta, num momento concreto, único, uma experiência espontânea, uma vivência direta.

No entanto, o momento haiku é somente a primeira condição na criação do haiku. Segundo Haruo Shirane (2000), dois eixos organizam o pequeno poema: o eixo horizontal e o eixo vertical. O primeiro, o horizontal, fixa o presente, a imagem concreta, a experiência direta, isto é, o momento haiku.

Os poemas dos poetas búlgaros e portugueses captam bem o momento haiku. A diferença passa pela temática das experiências: no haiku búlgaro, o inverno, a montanha, a neve, a cidade, aparecem mais vezes do que no haiku português; no haiku português vê-se o mar, sente-se a água, o vento. Muitas vezes o haiku búlgaro tem uma tonalidade lírica ao passo que o haiku português parece mais erótico, veja-se a obra de Casimiro de Brito, onde o erotismo é mais filosófico; um tom humorístico pode-se observar nos poemas búlgaros (por exemplo, nos de Petar Chuhov) e menos em poemas portugueses; alguns acentos filosóficos são mais visíveis no haiku português.

O eixo vertical coloca o sentido da imagem concreta além do momento haiku, além de aqui e agora, na memória cultural, nos mitos nacionais, nas associações mais abrangentes de espaço e de tempo. $\mathrm{O}$ haiku perfeito acontece no ponto de cruzamento deste dois eixos.

Vejamos os dois exemplos seguintes:

ao anoitecer / a lua em quarto crescente / sobre o arvoredo

(Leonilda Alfarrobinha, 2007: 57)

deitado no chão / o gato espreguiça o tempo; / depois, lambe o tédio (Luisa Freire, 2003: XXXI)

A diferença entre os dois poemas parece clara. No primeiro temos a imagem concreta, a presença da natureza, o instante do olhar. No segundo temos os dois eixos: o horizontal - "deitado no chão o gato"; e o vertical - "espreguiça o tempo, lambe o tédio", metáforas complexas que estimulam a imaginação, as memórias e as associações do leitor.

Ao nível do eixo vertical, a diferença entre o haiku búlgaro e o haiku português passa pela escolha de meios verbais necessários para 
introduzir este eixo no poema e também pelo conjunto de emoções e reflexões que surge no ponto de cruzamento dos dois eixos.

Portanto, agora a nossa pergunta é: quais são os mecanismos que as duas línguas mobilizam para a criação de um bom haiku?

Os mecanismos verbais que os especialistas indicam normalmente são a justaposição e/ou a superposição das duas partes do haiku. Entre estas duas partes existe sempre uma pausa, uma rutura. É aí que tudo acontece. Todo o valor do haiku reside nessa pausa.

Contudo, Richard Gilbert (2003) pensa que estas duas técnicas não são suficientes. Será a disjunção que confere o valor poético próprio ao haiku. É graças à disjunção que o leitor vive uma sensação de ausência, ambiguidade e imperfeição do sentido. Paradoxalmente, é esta sensação que confere a coerência ao poema que o leitor tenta alcançar.

Segundo Richard Gilbert a disjunção tem três funções: 1) uma função centrífuga: o leitor é levado para fora do poema, da imagem; 2) uma função gravitacional: o leitor entra numa contemplação introspetiva; 3 ) uma função semântica: o leitor experimenta um processo de perda/ganho de sentido. O efeito da disjunção é despertar um conhecimento intuitivo da essência das coisas.

Quais são as técnicas verbais que podem criar a disjunção? Vamos considerar só algumas técnicas mais importantes para o haiku e que aparecem com maior frequência nos poemas dos poetas búlgaros e portugueses:

- a fusão metafórica. Técnica bem usada em português e em búlgaro:

José Tolentino Mendonça:

Hospedo-me hoje nesta cabana / amanhã serei hóspede / da lua

Tsveta Djagarova-Omila:

Гнездо / на върха на дървото - / око към Бога ninho / no cimo da árvore- / um olho para Deus

Neste haiku temos a metáfora, ninho-olho. A preposição búlgara "kym" - "na direção de", "orientado para" - permite uma concisão extrema da metáfora. 
- simetria nas estrofes: técnica mais usada no haiku português: Luisa Freire:

De manhã, quarto minguante/à noite, quarto crescente - / lua mentirosa

- mudança de registo: técnica usada em português e em búlgaro:

Casimiro de Brito:

As ervas inclinam-se/indicam o paraíso / tão esquecido Petar Chuhov:

Внезапен дъжд / споделям чадъра си / с една статуя

De repente, chuva / partilho o meu guarda-chuva / com uma estátua - elementos de animismo: bastante frequentes:

Luisa Freire:

menina vaidosa/a borboleta volúvel - / dança em cor e asas

Elisaveta Chapkareva:

Ниско небе / размахват облаците / скъсани криле

Céu baixo / as nuvens agitam / asas rasgadas

- verdade impossível:

Dinis Lapa:

As gaivotas / calam-se / perante o silêncio

Liudmila Hristova:

Езеро с лотоси / няма място / за луната

Lótus no lago / não há lugar / para a lua 


\section{Conclusão}

Para resumir as características do haiku búlgaro e do haiku português, propomos a tabela seguinte que evidencia diferenças e semelhanças entre os haijins dos dois países:

\begin{tabular}{|c|c|c|c|c|}
\hline $\begin{array}{c}\text { Haiku } \\
\text { Europeu }\end{array}$ & $\begin{array}{l}\text { Características } \\
\text { socioculturais }\end{array}$ & $\begin{array}{c}\text { Caracte- } \\
\text { rísticas } \\
\text { estruturais } \\
\end{array}$ & $\begin{array}{c}\text { Técnicas } \\
\text { de disjunção } \\
\text { e justaposição }\end{array}$ & $\begin{array}{l}\text { Momentos } \\
\text { haiku }\end{array}$ \\
\hline $\begin{array}{c}\text { Haiku } \\
\text { português }\end{array}$ & $\begin{array}{l}\text { O haiku será } \\
\text { uma escola de } \\
\text { escrita. }\end{array}$ & $\begin{array}{c}\text { O haiku } \\
\text { português é } \\
\text { mais livre } \\
\text { e mais narra- } \\
\text { tivo. }\end{array}$ & $\begin{array}{l}\text { Fusão metafó- } \\
\text { rica, simetria } \\
\text { nas estrofes, } \\
\text { mudança } \\
\text { de registo, } \\
\text { elementos } \\
\text { de animismo }\end{array}$ & $\begin{array}{l}\text { o mar, o vento, } \\
\text { a água, } \\
\text { a viagem; } \\
\text { elementos de } \\
\text { erotismo; acen- } \\
\text { tos filosóficos }\end{array}$ \\
\hline $\begin{array}{l}\text { Haiku } \\
\text { búlgaro }\end{array}$ & $\begin{array}{c}\text { Pretende-se } \\
\text { criar uma es- } \\
\text { cola búlgara de } \\
\text { haiku. }\end{array}$ & $\begin{array}{l}\text { O haiku búl- } \\
\text { garo situa-se } \\
\text { mais perto } \\
\text { do cânone } \\
\text { original } \\
\text { e tem uma } \\
\text { estrutura } \\
\text { mais frag- } \\
\text { mentada. }\end{array}$ & $\begin{array}{l}\text { As mesmas } \\
\text { técnicas, mais } \\
\text { o paradoxo. } \\
\text { A simetria } \\
\text { nas estrofes- } \\
\text {-raramente }\end{array}$ & $\begin{array}{l}\text { o inverno, } \\
\text { a neve, } \\
\text { a montanha, } \\
\text { a cidade; tona- } \\
\text { lidade lírica; } \\
\text { humor }\end{array}$ \\
\hline
\end{tabular}

Observamos que as diferenças se situam sobretudo ao nível sociocultural e no que diz respeito aos tópicos temáticos.

O haiku ocupa cada vez mais espaço na vida literária dos nossos países. Será por causa da necessidade de procurar novas formas poéticas, novos princípios estéticos? Ou de encontrar um novo modelo de vida? Uma nova visão do mundo? Neste sentido, podemos citar Iztok Osojnik:

We have to play this most serious game that the language "happens to me", there is music and I dance, the game of pre-ontological exposition, $[\ldots]$.Thus one could say that a haiku is a true political event, the revolution if you want, as it clearly exposes the fact that being is outside global 
neoliberal capitalism and its spectacle of production of consumption [...]. Haiku is a supreme political act. (2011: speech 2)

\section{Referências bibliográficas}

BAN'YA, N. (2018), "Haiku and landscape”, World Haiku Anthology, 14, Tokyo.

KOREN, L. (2015), Wabi-Sabi, Further Thoughts, Imperfect Publishing, California.

KEMMOKU, M., CHIPOT, D. (2012), L'intégrale des haikus de Bashô, La Table Ronde, Paris.

METODIEV, I. (1990), “O estilo Nava (Stilyt Nava)”, Puls, 14, Sofia.

NUNES de ALMEIDA, C. (2015), Migração silenciosa. Marcas do pensamento estético do Extremo Oriente, Húmus, Lisboa.

SHIRANE, H., (2000), "Beyond the Haiku Moment", [on-line] https://www. thehaikufoundation.org/omeka/items/show/518.

GILBERT, R. (2003), "Disjunctive Dragonfly”, The Magazine of The World Haiku Club, 3(2).

OSOJNIK, I. (2011), “What Is Haiku?”, Speech 2, WHAC, 6, Tokyo.

\section{Lista dos poetas búlgaros e portugueses citados:}

ALFARROBINHA, L. (2007), O respirar das flores, Pássaro de Fogo, Lisboa.

BRITO, C. de (2000), Na via do Mestre, Pedra Formosa, Guimarães.

BRITO, C. de, TIMENOVA, Z. (2017), Escrito no vento, Eufeme, Leça da Palmeira.

CHUHOV, P., CHAPKAREVA, E. (2018), Beyond Words. Anthology, Farago, Sofia.

DJAGAROVA-OMILA, T., SAVOVA, V., HRISTOVA, L. P. (2014), Haiku sviat (Haiku Monde), 2, Iztok-Zapad, Sofia.

DOMINGOS, L. (2010), De frente para o mar, Palimage, Coimbra.

FREIRE, L. (2003), Imagens acidentais, Assírio e Alvim, Lisboa. LAPA, D. (2010), De frente para o mar, Palimage, Coimbra.

MENDONÇA TOLENTINO, J. (2013), A papoila e o monge, Assírio e Alvim, Lisboa. 